\title{
Evaluation of genotype $x$ environment interaction using GGE-biplot on dry beans (Phaseolus vulgaris L.) in Limpopo province of South Africa
}

\author{
Rudzani Mathobo $^{1,2^{*}}$, Diana Marais ${ }^{1}$ \\ ${ }^{1}$ Department of Plant and Soil Sciences, Faculty of Natural and Agricultural Sciences, University of Pretoria, \\ Private Bag X20, Hatfield 0028, South Africa \\ ${ }^{2}$ Limpopo Department of Agriculture, Private Bag X9487, Polokwane, 0700, South Africa
}

*Corresponding author: rudzanimathobo@gmail.com

\begin{abstract}
Dry bean is the second most important legume crop in South Africa due to its high protein content. GGE- Biplot was used to evaluate genotype $x$ environment interaction (GEI) and stability performance of dry bean genotypes during 2011 and 2012 growing seasons. Eight dry bean genotypes were planted at different locations in the Limpopo province, South Africa with different agro-climatic characteristics. The genotypes used were OPS-RS1, Jenny, Kranskop, DBS310, OPS-RS4, DBS 360, OPS-RS2 and OPS-RS5. The ANOVA analysis results for grain yield, number of pods per plant and number of seeds per plant revealed that the environment contributed more to the total variation followed by GEI and finally genotype. According to GGE biplot for grain yield, OPS- RS1 was regarded as the more stable genotype and had the highest mean yield, DBS 360 had the highest mean number of pods per plant and DBS 310 produced the highest mean number of seeds per plant. The GGE biplot methodology clearly presented the GEI relationship among environments and genotypes.
\end{abstract}

Keywords: G x E, GEI, number of pods per plant, number of seed per plant, stability analysis.

Abbreviations: ANOVA_analysis of variance, GEI_genotype by environment interaction, PCA_Principal Component Analysis, SVD_singular value decomposition.

\section{Introduction}

In South Africa dry bean is the third most important legume crop, with its domestic consumption (129 thousand tonnes) exceeding its production (65 thousand tonnes per annum). This implies that the local market is only able to supply $51 \%$ of the local consumption requirements while the balance is met through imports. To address food security challenge, the world relies on the development of highly productive and stable varieties of especially leguminous crops. Therefore variety trials are routinely conducted in order to compare a number of genotypes in multiple environments for multiple traits resulting in genotype by environment by trait three way data. Variety trials provide essential information for selecting and recommending crop cultivars (Yan and Tinker, 2006).

Many stability indices have been proposed, as reviewed by Lin and Binns (1994), and Yan and Kang (2003). Several researchers have published books and symposium proceedings to document the advances in the study of GE (Annicchiarico, 2002; Yan et al., 2007; Ding et al., 2008; Gauch et al., 2008; Yang et al., 2009; Alwala et al., 2010; Yan, 2014 ). Several studies concentrated more on quantification of GE and some are more concerned about matching genotypes with environments.

The gap between the two can be bridged by the use of biplot analysis methodology. According to Yan and Tinker (2006), a biplot is a scatter plot that approximates and graphically displays a two-way table by both its row and column factors such that relationships among row factors, relationship among the column factors, and the underlying interactions between the row and column factors can be visualized simultaneously. The first application of biplot to agricultural data analysis was done by Bradu and Gabriel (1978), using data from cotton. The term "GGE biplot" was proposed to address the questions relative to genotype $(\mathrm{G})$ by environment (E) data (Yan et al., 2000). The term "GGE" was used to emphasize the understanding that G and GE are the two sources of variation that are relevant to genotype evaluation. The GGE biplot is an effective method based on principal component analysis (PCA) to fully explore Multienvironmental data (Rao et al., 2011). The GGE biplot is constructed by plotting the first principal component (PC1) scores of the genotypes and the environments against their respective scores for the second principal component (PC2) resulting from singular value decomposition (SVD) of environment (Yan et al., 2007). The GGE biplot is an effective tool for mega-environment analysis (Yan and Holland, 2010), genotype evaluation and environmental evaluation (Ding et al., 2007). The most attractive feature of the GGE biplot is the "which-won-where" pattern of a genotype by environment dataset (Yan and Tinker, 2006). In "which-won-where" a polygon is first drawn on genotypes that are the furthest from the biplot origin so that all other genotypes are contained within the polygon. Then the perpendicular lines to each side of the polygon are drawn starting from the biplot origin. The genotypes located at the vertices of the polygon performed either the best or the poorest in one or more environments (Yan and Tinker, 2006). The "which-won-where" graphically displays the interaction between genotypes and environments, showing which 
genotype is best for which environment (Akinwale et al., 2014). The GGE biplot has been reported to be effective for GE interaction in oat (Yan et al., 2010), sorghum (Rao et al., 2011), wheat (Mohammadi and Amri, 2012; Rad et al., 2013), wheat-barley (Farshadfar et al. 2012), and chickpea (Farshadfar et al., 2013). The GGE biplot was used to genotypes ideal for production across drought, Striga and low nitrogen environments (Badu-Apraku et al., 2010) and was also used to identify mega environments for evaluating maize cultivars in West Africa (Badu-Apraku et al., 2011).

The objectives of this study was to (i) Evaluate the stability performance of the South African dry bean genotypes under different environmental conditions of the Limpopo province using GGE biplot methodology, (ii) examine the relationship among test environments, (iii) examine the relationship among genotypes and (iv) determine the relationship between genotypes and environments.

\section{Results}

Combined ANOVA for dry bean yields, number of pods per plant and number of seeds per plant for 2011 and 2012

The environments which were included in both seasons were treated as different environments since the performance of the genotypes differed significantly within the 2 years. It resulted in 6 tested environments. The combined analyses for dry bean yields, number of pods per plant and number of seeds per plant showed a highly significant $(\mathrm{P}<0.01)$ difference among environments, genotypes and GEI (Table 1). In terms of dry bean yields, number of pods per plant and number of seeds per plant, the following were observed: the environment (E) effect accounted for 70\%, 71\% and 78\% of the total sum of squares respectively. The genotype $(\mathrm{G})$ effect accounted for $5 \%, 4 \%$ and $3 \%$ of the total sum of squares respectively. The GE effect accounted for $22 \%, 21 \%$ and $18 \%$ of the total sum of squares respectively. The presence of GEI resulted in a change in genotype ranking across the environments.

\section{Principal component analysis (PCA) for dry bean yields, number of pods per plant and number of seeds per plant for 2011and 2012}

Principal component analysis was performed on yield, number of pods and number of seeds per plant. The first two principal components accounted for $96.88 \%$ of the variation with 63.68 and $33.20 \%$ for PC1 and PC2 respectively (Table 2 ). The first component was positively related to number of pods per plant and number of seeds per plant but negatively related to yield. The second component was related to yield.

\section{GGE-Biplot analysis for dry bean yields, number of pods per plant and number of seeds per plant for 2011 and 2012}

The partitioning of GEI through GGE biplot analyses showed that the first two principal components (PC1 and PC2) accounted for $77.5,81.4$ and $85.5 \%$ of the total variation for yield, number of pods per plant and number of seeds per plant, respectively (Figs 1a-c) .

\section{“Which- won- where” for dry bean yields, number of pods} per plant and number of seeds per plant

The vertex genotypes for yield were G7, G4, G3, G6, G5 and G2 with G4 performing the best at E5 while G7 was the best at E6 and G3 at E3 (Fig 1a). The pattern suggests that the target environment may consist of two mega-environments and that different genotypes should be selected to be planted in each of them. The vertex genotypes for number of pods per plant were G2, G5, G6, G4 and G7 with G6 being the best at E4, G2 was the best at E2 while G4 was the best at E3 (Fig 1b). The target environment may consist of four megaenvironments. The vertex genotypes for number of seeds per plant were G7, G2, G3, G6 and G4 with G4 being the second best at E5 and G7 being the best at E2 and E3 (Fig 1c). The target environment may consist of three mega-environments.

\section{Relationship among dry bean genotypes}

The distance between two genotypes approximates the Euclidean distance between them, which is a measure of the overall dissimilarity between them (Yan and Tinker, 2006). The presence of an acute angle between two genotypes suggests that they responded similarly, that the difference between them is proportional in all environments and that the difference between genotypes contributed more to $G$ than to GE. The presence of an obtuse angle suggests that the performance of the first genotype was good and for the second one poor. The presence of a right angle suggests that genotypes responded independently to different environments and the difference contributed mostly to GE. The results for yield indicated that genotypes G4, G3 and G1 are positively correlated since there is an acute angle between them (Fig 2a). Genotypes G3 and G5 are not correlated due to the right angle between them. . Genotypes G3 and G7 are negatively correlated due to the obtuse angle between them. The results for number of pods per plant indicated that G1, G4 and G6 are positively correlated, G2 and G7 are not correlated and G2 and G5 are negatively correlated (Fig $2 b$ ). The results for number of seeds per plant indicated that G1, G4, G5 and G6 are positively correlated, G7 and G3 are not correlated and G7 and G6 are negatively correlated (Fig 2c). The results for the measured traits indicated that there were similarities among genotypes with three or more similar genotypes.

\section{The relationship among environments}

The results for yield indicated that E3 and E4, E3 and E2, E6 and $\mathrm{E} 5$ are positively correlated since the angle between them is an acute angle (Fig 3a). The environment E5 and E4 are not correlated since the angle between them is a right angle. The environments E6 and E2 are negatively correlated since the angle between them is an obtuse angle. The results for number of pods per plant indicated that E6, E1 and E4 are positively correlated (Fig 3b). The environment E6, E5 and E2 are negatively correlated. The results for number of seeds per plant indicated that E3, E1 and E2 are positively correlated (Fig 3c). The environment E5 and E2 are negatively correlated. For yield and number of pods per plant the most discriminating (informative) environment is E2 since it had the longest vector from the biplot origin. E1 was the least discriminating environment for yield since its vector is the smallest. For number of pods per plant E3 was the least discriminating environment. For number of seed per plant the most discriminating environment was E2 and the least discriminating was E3.

\section{Performance of genotypes in specific environments}

The yield performance of G8 at E6, G7 at E3 and G3 at E2 
Table 1 Combined analysis of variance for pods per plant, seeds per plant and yield for all locations for all the years

\begin{tabular}{lccll}
\hline \multirow{2}{*}{ Source } & \multirow{2}{*}{ DF } & \multicolumn{3}{c}{ Mean squares } \\
\cline { 3 - 5 } & & Pods per plant & Seeds per plant & Yield \\
REP & 2 & 1.090 & 0.925 & $0.189^{* *}$ \\
ENV & 5 & $305.5^{* *}$ & $4081^{* *}$ & $17.39^{* *}$ \\
GEN & 7 & $11.12^{* *}$ & $115.36^{* *}$ & $0.909^{* *}$ \\
ENV GEN $_{\text {Error }}^{3 *}$ & 35 & $13.25^{* *}$ & $137.18^{* *}$ & $0.772^{* *}$ \\
\hline ** significant at $\mathrm{p}<0.01$ & 94 & 59.15 & 56.03 & 0.032 \\
\hline
\end{tabular}

A

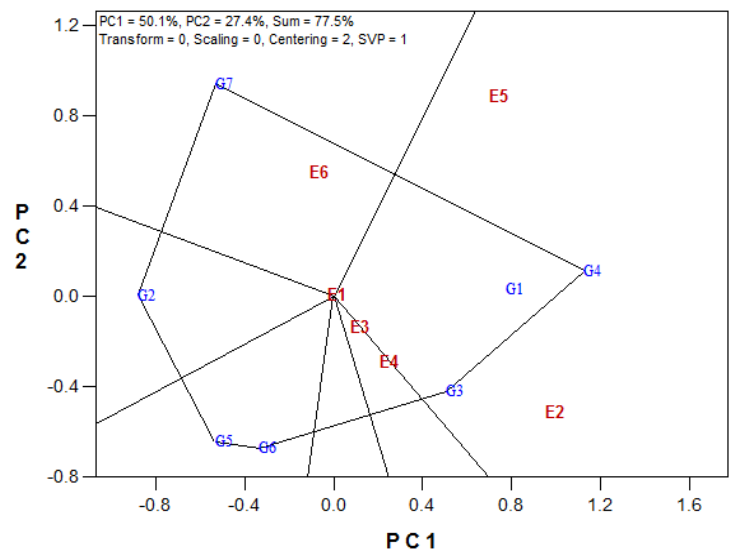

$\mathrm{B}$

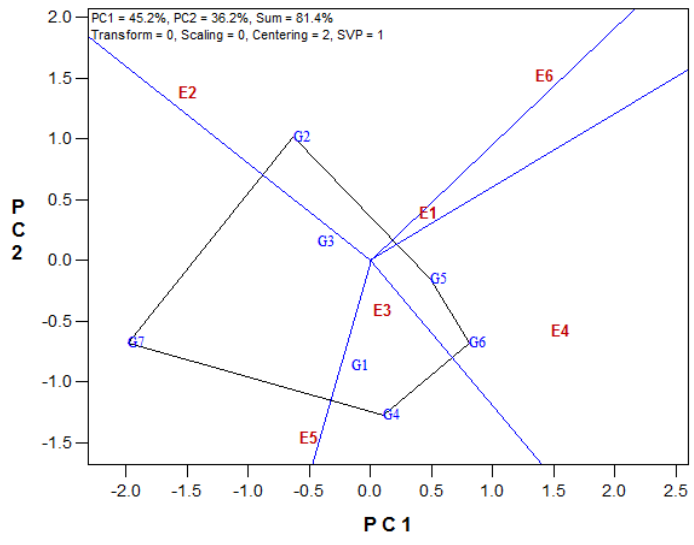

$\mathrm{C}$

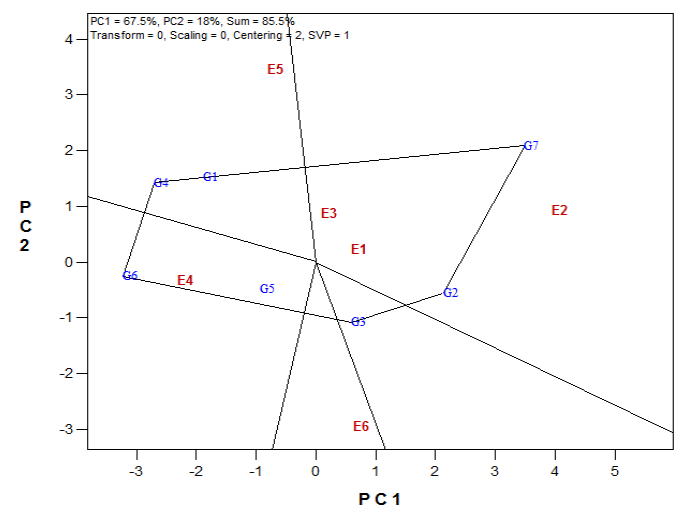

Fig 1. "Which genotype won where" for yield (a), number of pods per plant (b) and number of seeds per plant (c) for 2011 and 2012 based on the symmetrical scaling. Red numbering (E1 to E6) indicates environments and blue genotypes (G1 to G8). 
Table 2. Eigenvalue and eigenvectors from the three principal components axis for 2011 and 2012.

\begin{tabular}{llll}
\hline Parameter & PC1 & PC2 & PC3 \\
\hline Eigen values & 1.91 & 0.99 & 0.09 \\
\% variance & 63.68 & 33.20 & 3.12 \\
Cumulative \% & 63.68 & 96.88 & 100 \\
Characters & Eigenvector & & \\
Yield & -0.124 & 0.987 & 0.106 \\
Pods & 0.697 & 0.162 & 0.698 \\
Seeds & 0.706 & 0.012 & 0.708 \\
\hline
\end{tabular}

A

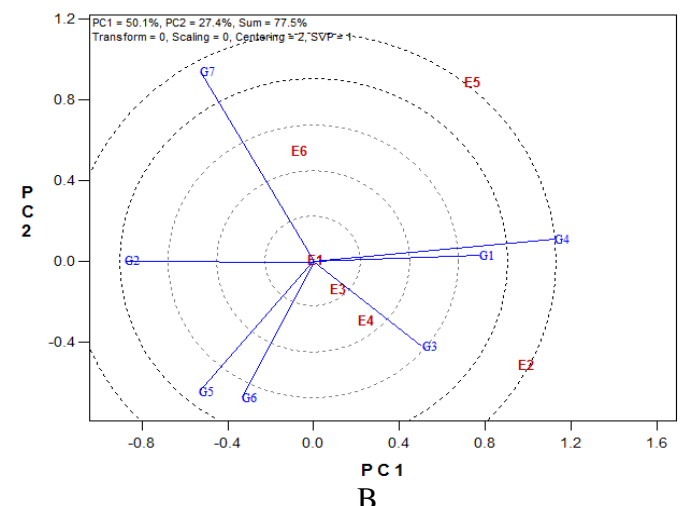

$\mathrm{B}$
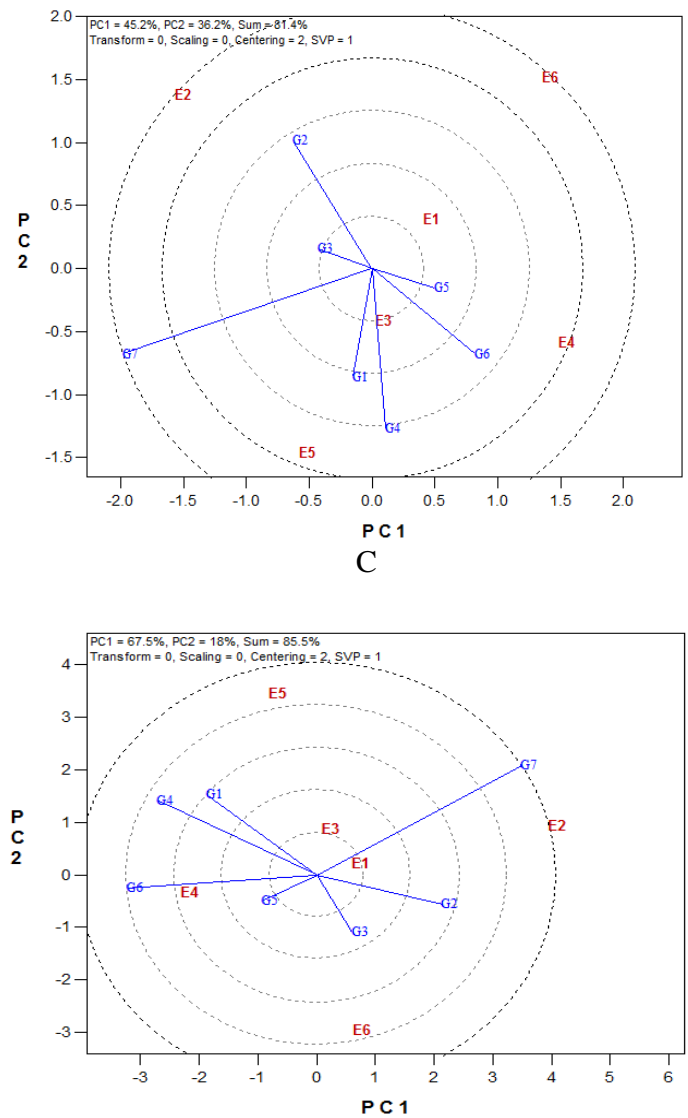

Fig 2. Similarities among dry bean genotypes for yield (a), number of pods per plant (b) and number of seeds per plant (c) for 2011 and 2012. Red numbering (E1 to E6) indicates environments and blue genotypes (G1 to G8) 
A

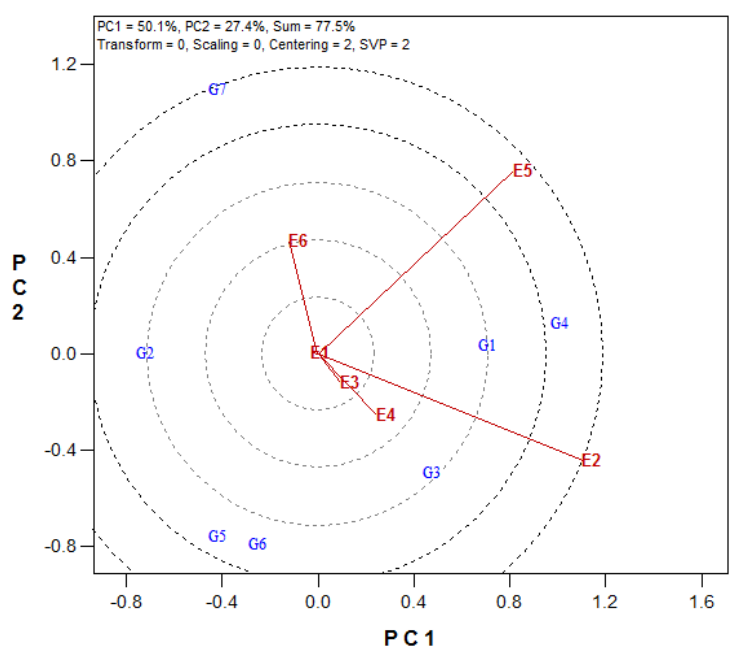

$\mathrm{B}$
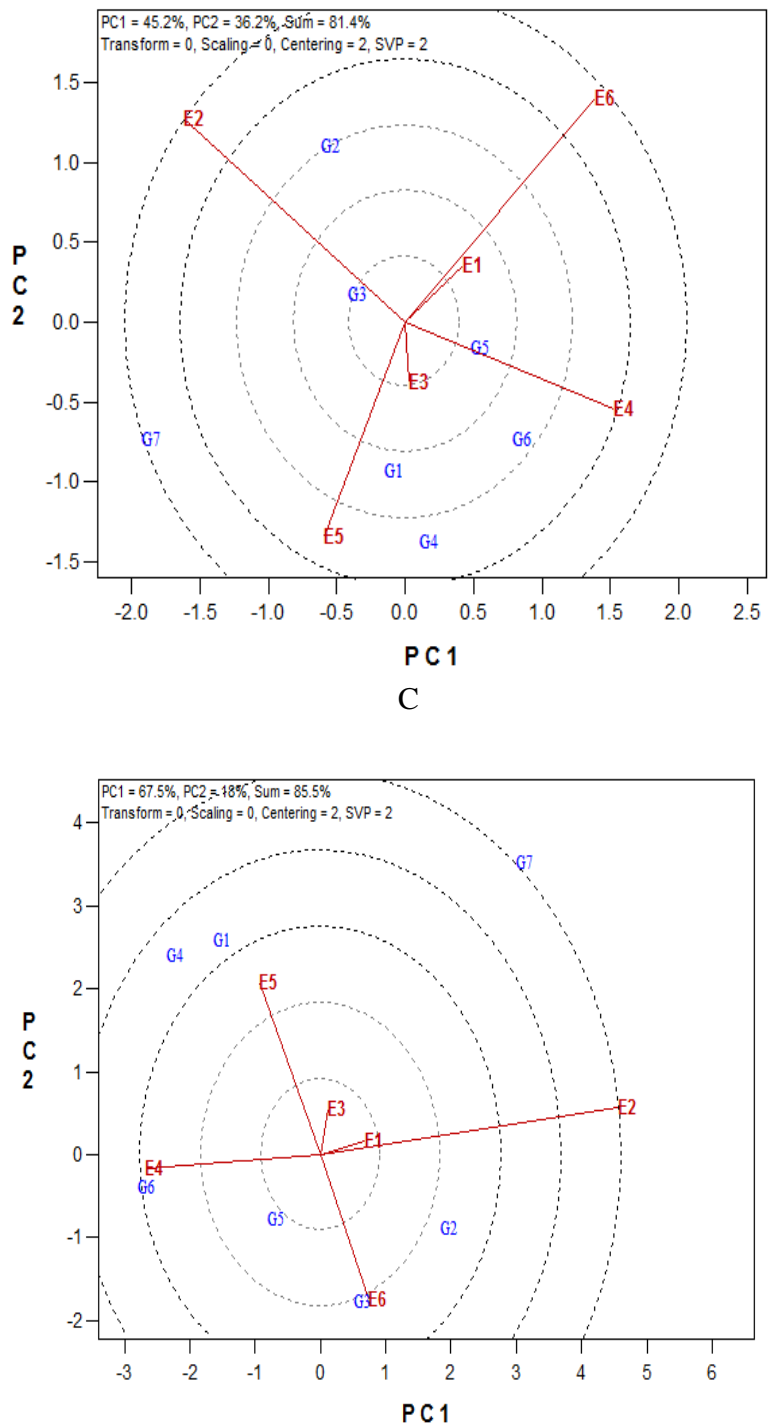

Fig 3. Relationship among environments for yield (a), number of pods per plant (b) and number of seeds per plant (c) for 2011 and 2012. Red numbering (E1 to E6) indicates environments and blue genotypes (G1 to G8). 
A

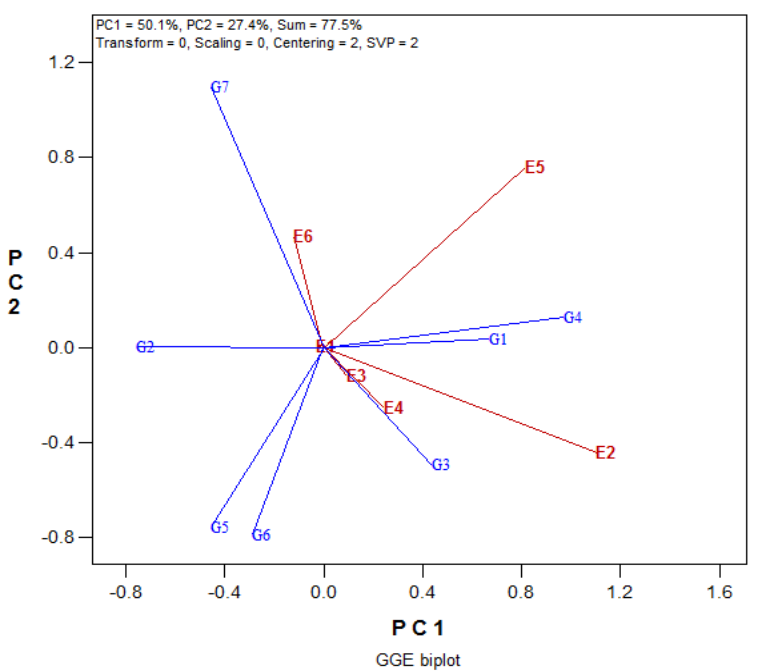

B
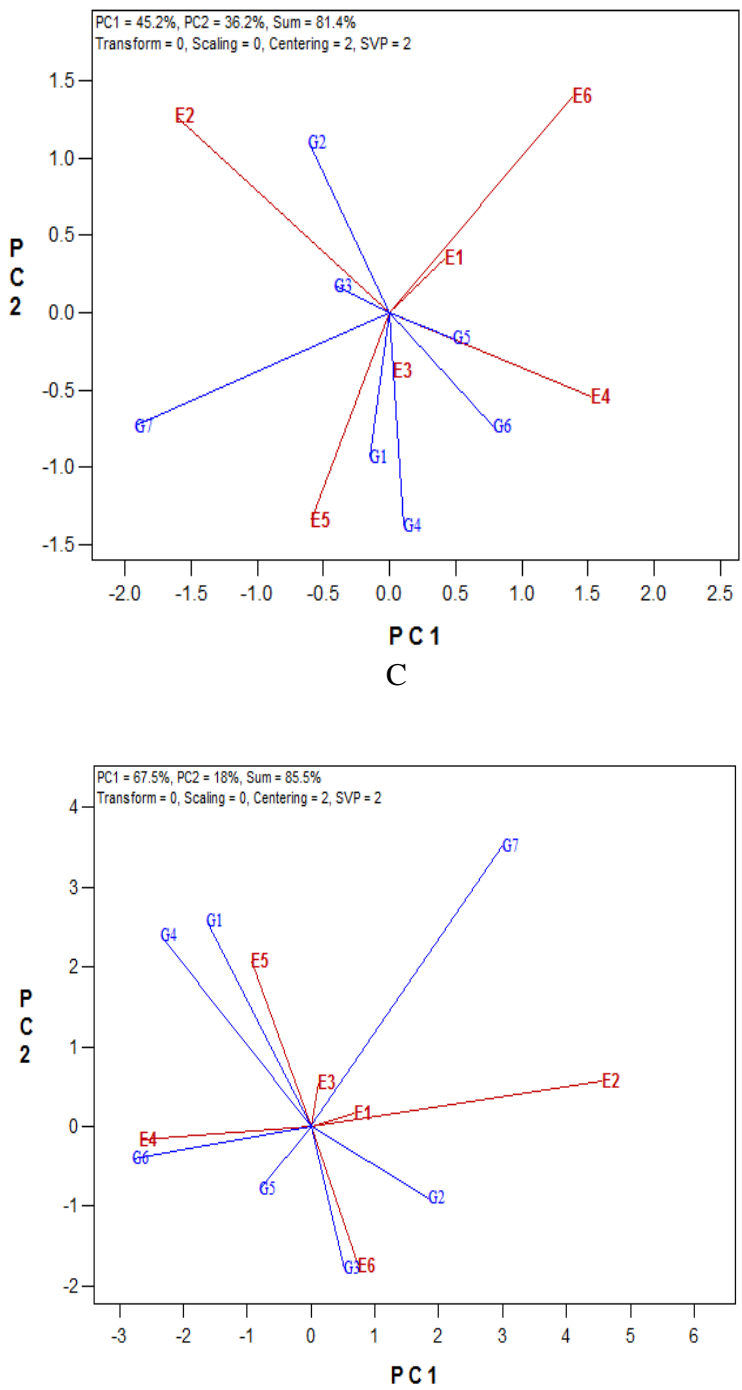

Fig 4. Performance of each dry bean genotype in each environment for yield (a), number of pods per plant (b) and number of seeds per plant (c) for 2011 and 2012. Red numbering (E1 to E6) indicates environments and blue genotypes (G1 to G8). 

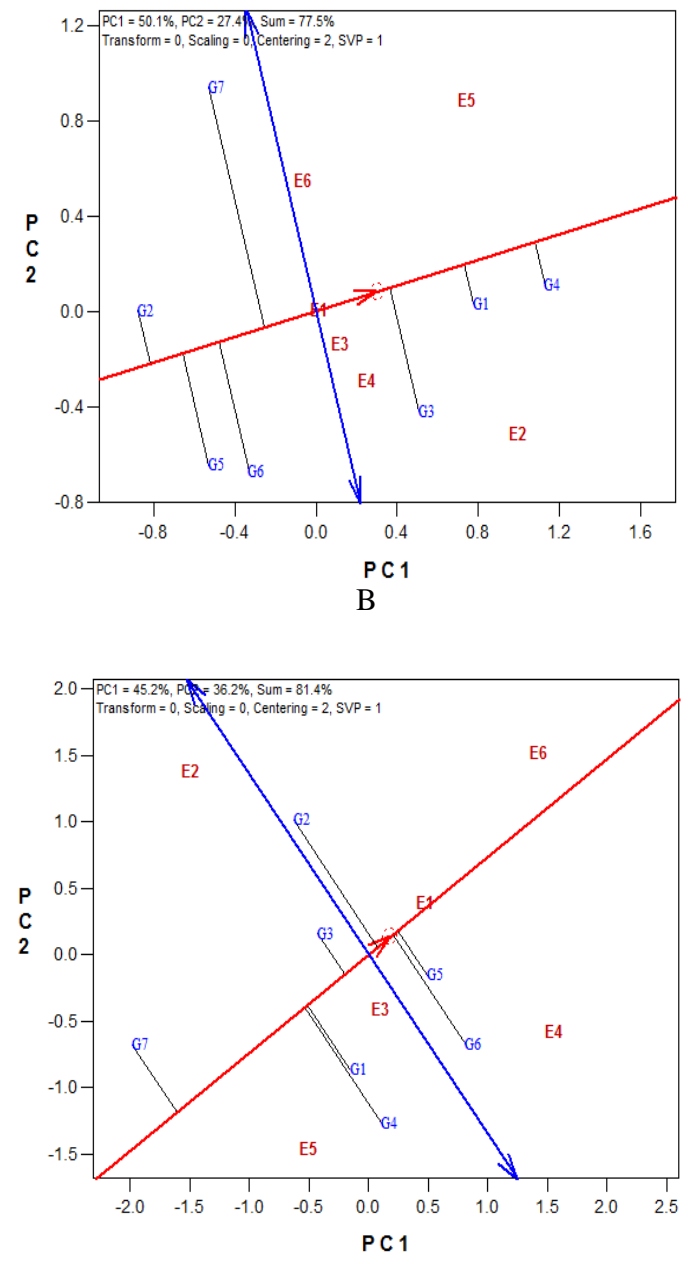

$\mathrm{C}$

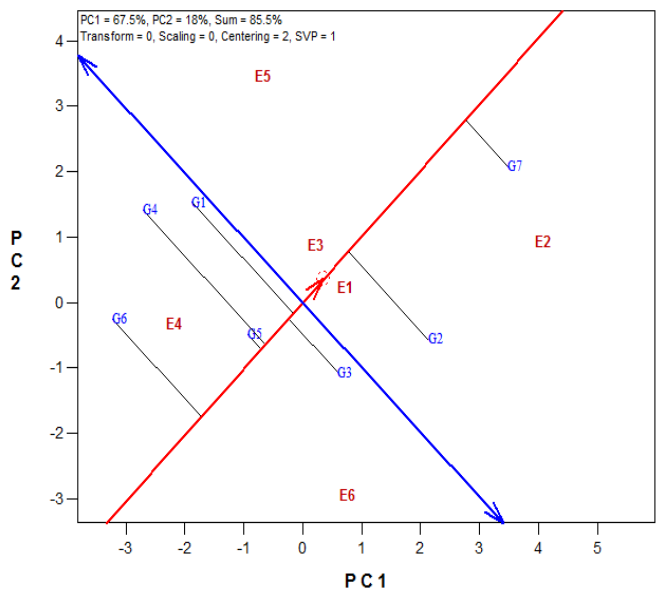

Fig 5 Ranking dry bean genotypes based on mean performance for yield (a), number of pods per plant (b) and number of seeds per plant (c). Red numbering (E1 to E6) indicates environments and blue genotypes (G1 to G8).

were above average since the angle between them is $<90^{\circ}$. The yield performance of G2 at E5 was poorer than average because the angle between them is $>90^{\circ}$ (Fig 4a). The number of pods per plant of G1 at E5 and G6 at E6 were above average. The number of pods per plant of G5 at E2 was poorer than average because the angle between them is $>90^{\circ}$
(Fig 4b). The number of seeds per plant of G1 at E5 and G5 at E6 were above average. The number of seeds per plant of G6 at E5 was near average since the angle is about $90^{\circ}$. The number of seeds per plant of G4 at E2 was poorer than average because the angle between them is $>90^{\circ}$ (Fig 4c). 


\section{Mean performance and stability of dry bean genotypes}

The genotype G4 had the highest mean yield, followed by G1 because they are on the far right hand side of the biplot towards the pointing arrow of the AEC abscissa (Fig 5a). The genotype G2 is regarded as consistently the lowest yielding genotype since it is positioned on the far left side of the biplot. The double-arrowed line is the AEC ordinate; it points to greater variability (poorer stability) in either direction. Thus, G4 and G1 are highly stable since they are positioned very near to the AEC abscissa with near zero PC2 scores and G7 was highly unstable since it is positioned very far away from AEC abscissa and has very high PC2 scores. The number of pods per plant analysis revealed that G5 had the highest mean number of pods per plant and G7 had the lowest mean number of pods per plant (Fig 5b). The most stable genotype was G3 and G2 was unstable. The number of seeds per plant analysis indicated that G7 had the highest mean number of seeds per plant and G6 had the lowest number of seeds per plant (Fig 5c). The most stable genotype in the number of seeds per plant was G5 and the most unstable was G4.

\section{Discussion}

Multi-environmental trials are very important for breeders in order to measure stability of different genotypes. The presence of GEI complicates the selection process as GEI reduces the usefulness of genotypes by confounding their yield performance through minimizing the association between genotypic and phenotypic values (Farshadfar et al., 2012). This can cause a genotype to perform well in one environment, but poorly in another. The combined analyses of the present study showed highly significant variation for environment, genotype and GEI for grain yield, number of pods per plant and number of seeds per plant. For all three traits environment accounted for 77.4, 87.9 and $85.5 \%$ of the total variation. This suggests that there were considerable differences between environments. The domination of environment has also been reported in studies on sugarcane (Alarmelu et al., 2015), maize (Munawar et al., 2013) and wheat (Rad et al., 2013; Mohammadi et al., 2010).

According to Yang et al. (2009) the first two principal components should account for $>60 \%$ of the $(G+G E)$ variability and the combined $(\mathrm{G}+\mathrm{GE})$ effect should account for $>10 \%$ of the $(E+G+G E)$ variability before claiming the usefulness of the biplots. Gauch and Zobel (1997) also concluded that the first two PCA are usually sufficient for making conclusions on. For this study the first two principal components (PC1 and PC2) accounted for $77.5 \%, 81.5 \%$ and $85.5 \%$ of the total variation of yield, number of pods per plant and number of seeds per plant respectively. Therefore biplots were used to evaluate the date further.

"Which-won-where" is one of the most attractive features of the GGE biplot, which graphically addresses the crossover GE, mega-environment differentiation, and more specifically adaptation (Rakshit et al., 2012). It also facilitates the identification of superior genotypes and the test environment that permit the detection of such genotype (Okonye et al., 2008). The genotypes on the vertices of the polygon performed either the best or the poorest in one or more environments (Yan and Tinker, 2006). The vertex genotypes for yield were G7, G4, G3, G6, G5 and G2 with G4 performing the best at E5 while G7 was the best at E6 and G3 at E3. The vertex genotypes for number of pods per plant were G2, G5, G6, G4 and G7 with G6 being the best at E4 while G2 was the best at E2. The vertex genotypes for number of seeds per plant were G7, G2, G3, G6 and G4 with G4 performing best at E5 andG7 being the best at E2 and E3. The environments within the same sector share the same winning genotype and environments in different sectors share different winning genotypes. The identification of best cultivar for each location using "Which-won- where" was previously reported in proso millet (Zhang et al., 2016) and cotton (Xu et al., 2014).

The cosine angle between the vectors of the two environments approximates the correlation between them (Yan and Rajcan, 2002). The presence of the acute angle between E3 and E4, E3 and E2, E6 and E5 suggests that the same information about the genotypes can be obtained from one of the two environments. Environments like E2, E3 and E4 can be replaced by one environment in future yield trials without losing much information about the genotypes. Similary, for number of pods per plant and number of seeds per plant, environments like E6, E1 and E4 and E2, E3 and E1 respectively can be replaced by one environment in future trials. The identification of the relationships among test environment using GGE biplot has been reported in wheatbarley (Farshadfar et al., 2012).

According to Yan and Tinker (2006), the performance of a genotype is better than the average if the angle between its vector and the environment's vector is $<90^{\circ}$; It is poorer than average if the angle is $>90^{\circ}$ and it is near average if the angle is about $90^{\circ}$. The yield performance of G8 at E6, G7 at E3 and G3 at E2 were above average since the angle between them is $<90^{\circ}$. The number of pods per plant of G1 at E5 and G6 at E6 were above average. The number of seeds per plant of G1 at E5 and G5 at E6 were above average. The number of seeds per plant of G6 at E5 was near average since the angle is about $90^{\circ}$. The visualization of the performance of genotypes in each environment using GGE biplot was reported in barley (Jalata, 2011).

The performance and stability of genotypes were evaluated by an average environment coordination (AEC) method (Yan, 2001). The results revealed that G4 was the highest performing and very stable for yield. For number of pods per plant G5 had the highest mean and G3 was the most stable. For the number of seeds per plant G7 had the highest mean and G5 was the most stable genotype.

\section{Materials and Methods}

\section{Site characterization}

The locations for 2011 and 2012 were Trichardtsdal $\left(24^{0} 10^{`} 0 \mathrm{~S}, 30^{0} 23^{\circ} 6 \mathrm{E}\right)$, Dzindi irrigation Scheme $\left(23^{\circ} 01^{`} 45 \mathrm{~S}\right.$ and $\left.30^{\circ} 26^{\circ} 30 \mathrm{E}\right)$, Phalaborwa $\left(23^{\circ} 55^{\circ} \mathrm{OS}, 30^{\circ} 59^{\circ} 4 \mathrm{E}\right)$ and Tshiombo $\left(22^{0} 48^{\circ} \mathrm{OS}, 30^{0} 33^{\circ} \mathrm{OE}\right)$. In 2012 the Trichardtsdal site fell out while Tshiombo came in. Trichardtsdal is situated about $50 \mathrm{~km}$ from Tzaneen town in Greater Tzaneen local Municipality (Mopani district), Dzindi irrigation Scheme is situated about $6 \mathrm{~km}$ from Thohoyandou town in Thulamela local municipality (Vhembe district), Tshiombo irrigation scheme is situated about $30 \mathrm{~km}$ from Thohoyandou town in Thulamela local municipality (Vhembe district) and Phalaborwa Mashishimale is situated about $15 \mathrm{~km}$ from Phalaborwa town in Ba-Phalaborwa local municipality (Mopani district).

\section{Plant material}

Eight genotypes of dry beans were planted in the 2011 and 2012 seasons at four locations with different agro-climatic conditions in Limpopo, South Africa. All the sites were under 
irrigation. The genotypes used were Kranskop (G1), OPSRS4 (G2), Jenny (G3), OPS-RS1 (G4), DBS 360 (G5), OPSRS2 (G6), DBS310 (G7) and OPS-RS5 (G8). The environments were Dzindi2011 (E1), Trichardtsdal (E2), Phalaborwa2011 (E3), Dzindi2012 (E4), Phalaborwa2012 (E5) and Tshiombo (E6). A randomized complete block design with three replications was used at each location. The plots consisted out of 4 rows each $5 \mathrm{~m}$ in length. A within row spacing of $7.5 \mathrm{~cm}$ and between row spacing of $90 \mathrm{~cm}$ were used giving a population of 150000 plants ha $^{-1}$.

\section{Traits measurements}

All the management practices were done according to the production practices (Liebenberg et al., 2002). Planting and weeding was done by hand. Data were collected from the two middle rows to border effects. Harvesting was done when the plant had reached maturity and natural drying was done. Yield was expressed at $10 \%$ seed moisture. The following data were collected at harvest 100 seed weight, number of seeds per pod, number of pods per plant, these were measured from 10 randomly selected plants per plot during maturity in the two middle rows. The moisture content, unshelled and shelled grain weight was also collected. The grain yield data was collected from one square metre in the centre of the plot.

\section{Statistical analysis}

The grain yield data were subjected to separate and combined analysis of variance (ANOVA) to determine the effects of environment, genotype and their interactions. The data were graphically analysed for interpreting the GE interaction using GGE biplot software (Yan, 2001). The GGE biplot methodology is composed of two concepts, the biplot concept and the GGE concept (Yan et al., 2000).

\section{Conclusion}

The study revealed a significant GEI which resulted in the change in ranking and also complicating the selection process of genotypes. This study revealed the efficiency of the GGEbiplot methodology for selecting genotypes that are stable and high yielding. The genotype which performed very high in terms of yield and was stable is OPS-RS1, while OPS-RS4 was the poorest and DBS310 the most unstable. For the number of pods per plant, DBS360 had the highest mean number of pods per plant and DBS310 had the lowest mean number of pods per plant. The most stable genotype was Jenny while OPS-RS4 was unstable. The number of seeds per plant analysis indicated that DBS310 had the highest and OPS-RS2 the lowest number of seeds per plant. The most stable genotype in regards to the number of seeds per plant was DBS360 and the most unstable was OPS-RS1. The results also suggest that for yield OPS-RS1 can be the best variety for environments Dzindi2011, Trichardtsdal, Phalaborwa2011, Dzindi2012, and Phalaborwa2012 while DBS360 can be selected for Tshiombo. The GGE biplot was able to reveal similarities and dissimilarities between genotypes and environments. The correlated environments can be represented by one environment in future to save costs and time.

\section{Acknowledgement}

We thank the Limpopo Department of Agriculture and Rural development for the financial support during this study.

\section{References}

Akinwale RO, Fakorede MAB, Badu-Apraku B, Oluwaranti A (2014) Assessing the usefulness of GGE biplot as a statistical tool for plant breeders and agronomists. Cereal Res Commun. 42: 534-546.

Alarmelu S, Balakrishnan R, Hemaprobha G (2015) G x E interaction studies in multi-location trials of sugarcane using GGE biplot and anom analysis. J Sugarcane Res. 5: 12-23.

Alwala S, Kwolek T, McPherson M, Pellow J, Meyer D (2010) A comprehensive comparison between Eberhart and Russell joint regression and GGE biplot analyses to identify stable and high yielding maize hybrids. Field Crops Res. 119: 225-230.

Annicchiarico P (2002) Genotype x Environment Interactions - Challenges and opportunities for plant breeding and cultivar recommendations. FAO Plant Production and Protection paper 174. Food and Agriculture Organization of the United Nations, Rome. www.fao.org/DOCREP/005/Y4391e00.htm Accessed on the $05 / 11 / 2009$.

Badu-Apraku B, Akinwale RO, Menkir A, Coulibaly N, Onyibe JE, Yallou GC, Abdullai MS, Didjera A (2011) Use of GGE biplot for targeting early maturing maize cultivars to mega-environment in West Africa. Afr Crop Sci J. 19:79-96.

Badu-Apraku B, Menkir A, Ajala SO, Akinwale RO, Oyekunle M, Obeng-Antwi K (2010) Performance of tropical early maturing maize cultivars in multiple stress environments. Can J Plant Sci. 90:831-852.

Bradu D, Gabriel KR (1978) The biplot as a diagnostic tool for models of two-way tables. Technometrics, 20: 47-68.

Ding M, Tier B, Yan W (2007) Application of GGE biplot analysis to evaluate genotype $(\mathrm{G})$, environment $(\mathrm{E})$ and $\mathrm{G} \mathrm{x}$ E interaction on P. radiata: A case study. Paper presented to Australasian Forest Genetics Conference Breeding for Wood Quality, 11-14 April 2007, Hobart, Tasmania, Australia.

Ding M, Tier B, Yan W, Wu HX, Powell MB, McRae T A (2008) Application of GGE biplot analysis to evaluate Genotype (G), Environment (E), and G×E interaction on Pinus radiata: a case study. New Zeal J For Sci. 38: 132142.

Farshadfar, E, Mohammadi, R, Aghaee, M, Vaisi, Z (2012) GGE biplot analysis of genotype $x$ environment interaction in wheat-barley disomic addition lines. Afr J Crop Sci. 6, 1074-1079.

Farshadfar E, Rashidi M, Jowkar MM, Hassan Zali H (2013) GGE- Biplot analysis of genotype $\times$ environment interaction in chickpea genotypes. Eur J Exp Biol. 3: 417423.

Gauch HG, Piepho HP, Annicchiarico P (2008) Statistical Analysis of Yield Trials by AMMI and GGE: Further Considerations. Crop Sci. 48, 866-889.

Gauch HG, Zobel RW (1997) Identifying mega-environments and targeting genotypes. Crop Sci. 37: 311-326.

Jalata Z (2011) GGE- biplot analysis of multi-environment yield trials of barley (Hordeium vulgare L.) genotypes in South eastern Ethiopia Highlands. Int J Plant Breed Genetics. 5:59-75.

Kang M. S. (2003) Quantitative genetics, genomics, and plant breeding. CAB International, Wallingford, UK.

Liebenberg AJ, Van Wyk C, Trent C, Swanepoel SC, Mcdonald A, Els IJ (2002) Dry bean production manual. Agricultural Research Council Grain Crops Institute, Potchefstroom. 
Lin CS, Binns MR, 1994 Concepts and methods for analyzing regional trial data for cultivar and location selection. Plant Breed Rev. 12: 271-297.

Mohammadi R, Amri A (2012) Analysis of genotype environment interaction in rain-fed durum wheat of Iran using GGE-biplot and non- methods. Can J Plant Sci. 92: 757-770.

Mohammadi R, Roostaei M, Ansari Y, Aghaee, M, Amri M (2010) Relationships of phenotypic stability measures for genotypes of three cereal crops. Can J Plant Sci. 90: 819830.

Munawar M, Hammad G, Shahbaz M (2013) Evaluation of maize (Zea mays $L$ ) hybrids under different environments by GGE biplot analysis. American-Eurasian J Agric Environ Sci. 13: 1252-1257.

Rad MRN, Kadir MA, Rafii MY, Jaafar HZE, Naghavi MR, Ahmadi F (2013) Genotype x environment interaction by AMMI and GGE biplot analysis in three consecutive generations of wheat (Triticum aestivum) under normal and drought stress conditions. Aust J Crop Sci. 7: 956-961.

Rakshit S, Ganapathy KN, Gomashe SS, Rathore A, Ghorade RB, Kumar NMV, Ganesmurthy K, Jain SK, Kamtar MY, Sachan JS, Ambekar SS, Ranwa BR, Kanawade DG, Balusamy M, Kadam D, Sarkar A, Tonapi VA, Patil JV (2012) GGE biplot analysis to evaluate genotype, environment and their interactions in sorghum multi-location data. Euphytica, 185:465- 479.

Rao PS, Reddy PS, Rathore A, Reddy BVS, Panwar, S (2011) Application of GGE biplot and AMMI model to evaluate sweet sorghum (Sorghum bicolor) hybrids for genotype $\mathrm{x}$ environment interaction and seasonal adaptation. Indian J Agr Sci. 81: 438-444.

Xu N Y, Fok M, Zhang G W, Li J, Zhou Z G. 2014. The application of GGE biplot analysis for evaluating test locations and mega-environment investigation of cotton regional trials. J Integr Agric. 13, 1921-1933.

Yan W (2001) GGE biplot- a Windows application for graphical analysis of multi-environment trial data and other types of two-way data. Agron J. 93: 1111-1118.

Yan, W (2014) Crop Variety Trials: Data Management and Analysis. Wiley-Blackwell, 360 pp. UK.
Yang RC, Crossa J, Cornelius PL, Burgueno J (2009) Biplot Analysis of Genotype $\times$ Environment Interaction: Proceed with Caution, Crop Sci. 49:1564-1576.

Yan W, Frégeau-Reid J, De Haan B, Pageau D, Lajeunesse J, Martin R, Cummiskey A, Mitchell-Fetch J, Etienne M, Rowsell J, Scott P, Price M, Durand J, Sparry E, 2010. Identifying essential test locations for oat breeding in Eastern Canada. Crop Sci. 50:504-515.

Yan W, Hunt LA, Sheng Q, Szlavnics Z (2000) Cultivar evaluation and mega environment investigation based on the GGE biplot. Crop Sci. 40: 597-605.

Yan W, Kang MS (2003) GGE Biplot Analysis: A Graphical Tool for Breeders, Geneticists and Agronomists. $1^{\text {st }} \mathrm{Ed}$, CRC Press LLC, Boca Roton, Florida, p. 271.

Yan W, Kang MS, Ma B, Woods S, Cornelius PL (2007) GGE biplot vs. AMMI analysis of genotype-byenvironment data. Crop Sci. 47:643-655.

Yan W, Rajcan I (2002) Biplot analysis of test sites and trait relations of soybean in Ontario. Crop Sci. 42:11-20.

Yan W, Tinker NA (2006) Biplot analysis of multienvironment trial data: Principles and applications. Can J Plant Sci. 86: 623-645.

Yan W K, Holland J B. 2010. A heritability-adjusted GGEbiplot for test environment evaluation. Euphytica. 171: 355369.

Zhang P, Song H, Ke X, Jin X, Yin L, Liu Y, Qu Y, Su W, Feng N, Zheng D, Feng B (2016) GGE biplot analysis of yield stability and test location representativeness in proso millet (Panicum miliaceum L.) genotypes. J Integr Agric. 15: $1218-1227$ 